\title{
Os bastidores de um estudo etnográfico: trilhando os caminhos teórico-empíricos para desvendar as culturas organizacionais de uma livraria de shopping center
}

\section{The backstage of an ethnographic research: tracing the theoretical and empirical paths to unveil the organizational cultures of a shopping mall bookstore}

\author{
Maria Tereza Flores-Pereira ${ }^{1}$ \\ Neusa Rolita Cavedon ${ }^{2}$
}

\begin{abstract}
Resumo
No presente artigo, procura-se evidenciar a construção do conhecimento administrativo mediante utilização do método etnográfico. O enfoque dado privilegiou os bastidores de uma pesquisa etnográfica, os processos de escolha, a inserção e a saída do campo. Permeando a descrição desses processos estão as vivências de estranhamento, de familiaridade e de desconstrução da pesquisadora. A trajetória de uma das autoras deste artigo é relatada com o intuito de auxiliar outros pesquisadores, que optarem pela realização de estudos etnográficos na área de Administração, a compreender o passo a passo do processo investigativo. Além da familiarização de outros pesquisadores em Administração com o método etnográfico, a produção deste artigo também teve como objetivo destacar a importância de se considerar os corpos do pesquisado e do pesquisador como sujeito criador de conhecimento na temática da cultura organizacional.
\end{abstract}

Palavras-chave: etnografia; cultura organizacional; corpo; embodiment; livraria; shopping center.

\section{Abstract}

This paper aims at exploring how the knowledge on organizations can be constructed through the ethnographic method. The focus of this work is the backstage of an ethnographic research, the process through which the choices, the insertion and the farewell of the research field were made. Intertwined with the description of the processes, the experiences of strangeness, familiarity and deconstruction of the researcher are also presented. The trajectory of one of the authors of this paper is included in the work in order to help other researchers, who choose to use the ethnographic method in Management studies, to understand the investigative process step by step. In addition to that, this paper also presents the analysis of the importance of considering the body of the researched and researcher as a subject that creates knowledge for the thematic or organizational culture.

Keywords: ethnography; organizational culture; body; embodiment; bookstore; shopping mall.

\footnotetext{
${ }^{1}$ Doutora, mestre e bacharel em Administração pela UFRGS. Doutorado sanduíche pela HEC Montréal. Bolsista de Pós-doutorado Júnior (PDJ-CNPq) pela Universidade Federal do Rio Grande do Sul (UFRGS).Endereço: Rua São Manoel, 132 apt. 602 - Rio Branco - Porto Alegre/Rio Grande do Sul - Brasil - CEP: 90620110. E-mail: mtfpereira@terra.com.br

${ }^{2}$ Doutora em Administração pelo Programa de Pós-Graduação em Administração da Universidade Federal do Rio Grande do Sul. Mestre em Administração pelo PPGA/EA/UFRGS e Mestre em Antropologia Social pelo PPGAS/UFRGS. Professora Adjunta da Escola de Administração da Universidade Federal do Rio Grande do Sul. Endereço: Universidade Federal do Rio Grande do Sul, Escola de Administração, Departamento de Ciências Administrativas. Av. Washington Luiz n. 855, sala 431 - Centro - Porto Alegre, RS - Brasil. CEP:

90010-460. E-mail: nrcavedon@ea.ufrgs.br

Artigo submetido em maio e aceito em junho de 2008
} 


\section{Introdução}

No presente artigo, procura-se evidenciar a construção do conhecimento administrativo valendo-se da utilização do método etnográfico. O enfoque dado privilegiou os bastidores de uma pesquisa etnográfica, os processos de escolha, a inserção e a saída de campo. Permeando a descrição desses processos estão as vivências de estranhamento, de familiaridade e de desconstrução da pesquisadora. A trajetória de uma das autoras deste artigo é relatada no intuito de auxiliar outros pesquisadores, que optarem pela realização de estudos etnográficos na área de Administração, a compreender o passo a passo do processo investigativo.

A pesquisa realizada mediante a utilização do método etnográfico teve como objetivo inicial articular uma relação entre a disciplina Antropologia do Corpo e os estudos de cultura organizacional. A questão e os objetivos sofreram uma mutação no decorrer da pesquisa, o que ocorreu, principalmente, em virtude de um processo de amadurecimento teórico da pesquisadora.

Antes da entrada em campo, no projeto de pesquisa, o objetivo estava fundamentado exclusivamente na dimensão simbólica dos estudos de corpo. O objetivo era: desvendar as culturas organizacionais por meio da análise simbólica dos corpos de seus trabalhadores. Num segundo momento, durante a produção do relato etnográfico, um aprofundamento teórico nos estudos de embodiment acarretou um amadurecimento no que diz respeito à contribuição que a pesquisa apresentava. Construiu-se, então, um novo objetivo que contemplasse tanto a dimensão simbólica, quanto uma perspectiva fenomenológica de estudo do corpo e, portanto, da cultura organizacional. O objetivo passou a ser repensar os estudos de cultura organizacional com base na análise simbólica e fenomenológica dos corpos dos trabalhadores.

O estudo etnográfico a ser descrito foi realizado principalmente durante o ano de 2005, num período acumulado de aproximadamente seis meses. Trata-se de uma etnografia de uma livraria de shopping center, aqui denominada como SerLivro, que tinha como grupo principal de informantes a equipe de vendedores. Para estudar o corpo do vendedor, suas representações e sua relação pré-reflexiva (portanto, corporal) com a organização, esses trabalhadores foram acompanhados não apenas no espaço da loja, mas também em suas atividades de almoço, de lanches e em algumas atividades de lazer (happy-hours, festas e um show de rock).

Para desvendar os caminhos desse estudo etnográfico, este artigo foi organizado em cinco seções, além desta introdução. Na primeira será apresentada uma teorização acerca do método etnográfico de modo a demonstrar algumas orientações com as quais a pesquisadora entrou em campo. Depois, inspirando-se na sequiência proposta por Baztán (1995), são abertas três seções referentes ao campo SerLivro: "Delimitando o campo" (seção 2), "Entrando em campo" (seção 3), e "Saindo do campo e produzindo o relato" (seção 4). Nestas três seções encontram-se descritos os bastidores do campo SerLivro e, junto com isso, informações que possam vir a facilitar o caminho de outros pesquisadores que venham a optar pelo método etnográfico em suas próprias pesquisas. No item final são discutidas as contribuições deste artigo para o campo dos estudos organizacionais.

\section{O método etnográfico}

O método etnográfico começa a ser utilizado em pesquisas no final do século XIX e início do século XX. Contrapondo-se ao etnocentrismo, consiste em buscar a compreensão de uma dada realidade cultural à luz do seu próprio contexto social, mediante a compreensão dos significados revelados pelos próprios nativos (VÍCTORA, KNAUTH e HASSEN, 2000).

Baztán (1995) afirma que a etnografia consiste na realização de um estudo descritivo sobre uma determinada comunidade, e em que o trabalho de campo, de modo particular a observação participante, constitui-se no processo, e o relato de cunho monográfico, no produto. Esse autor procurou evidenciar as etapas do processo etnográfico. A primeira etapa corresponde à delimitação do campo, ou seja, qual o objeto a ser investigado, a localização, o tempo de permanência previsto para a coleta de dados. O momento seguinte requer uma primeira investigação sobre as fontes documentais disponíveis para a obtenção de elementos que elucidem aspectos 
atinentes ao objeto a ser investigado. A seguir o pesquisador deve inserir-se no campo e manter o registro sistemático, por meio de notas de campo e do diário de campo, daquilo que ele observa no dia-a-dia em contato com a comunidade pesquisada. Nessa ocasião, o pesquisador elege os informantes, procurando distinguir entre eles aqueles que são porta-vozes do discurso oficial e aqueles que falam de modo mais livre sobre a cultura da qual fazem parte.

Na etapa de permanência no campo, o pesquisador irá confrontar a sua cultura com a cultura investigada. Tais comparações devem ser registradas como forma de tornar evidentes as perspectivas êmica (dos pesquisados) e ética (do etnógrafo). Munido de uma gama considerável de informações sobre aquela cultura, o pesquisador deve deixar o campo para produzir o seu relato.

Durante a sua estada no campo, o pesquisador deve ter a disciplina de redigir diariamente, daí o nome "diário de campo", o relato daquilo que ocorreu ao longo do tempo em que esteve entre os nativos. Outrora, o diário de campo era manuscrito, hoje, o meio eletrônico pode substituir o antigo caderno de capa dura, porém, o detalhamento e as impressões pessoais do pesquisador continuam sendo prerrogativas essenciais para a realização de uma pesquisa acurada (VÍCTORA, KNAUTH e HASSEN, 2000).

Baztán (1995) não faz referência a uma volta ao campo caso o etnógrafo perceba pontos obscuros em seu diário e notas de campo, mas tal prática tem se revelado razoavelmente freqüente, especialmente quando a comunidade pesquisada é a do próprio pesquisador, o que torna mais fácil uma possível reaproximação com os informantes.

Vale destacar que fazer etnografia requer dois movimentos, um de aproximação com a comunidade investigada, mediante uma imersão naquela realidade, e um afastamento para permitir posteriormente a análise. Clifford (1998, p. 33) refere-se a isso como um 'contínuo vai e vem entre o 'interior' e o 'exterior' dos acontecimentos: de um lado, captando o sentido de ocorrências e gestos específicos, através da empatia; de outro, dá um passo atrás, para situar esses significados em contextos mais amplos".

É, ainda, Clifford (1998) que alerta para o fato de a etnografia implicar uma dialética entre experiência e interpretação. Este autor (1998, p. 36), baseando-se em Dilthey, afirma que:

[...] a "experiência" etnográfica pode ser encarada como a construção de um mundo comum de significados, a partir de estilos intuitivos de sentimento, percepção e inferências. Essa atividade faz uso de pistas, traços, gestos e restos de sentido antes de desenvolver interpretações estáveis.

A experiência do etnógrafo em campo tem lhe garantido a autoridade etnográfica no sentido de quem esteve lá e, portanto, pode falar com legitimidade sobre o objeto estudado. Essa autoridade, de acordo com Clifford (1998), muitas vezes se expressa no modo como o pesquisador se refere ao campo;em afirmações do tipo "o meu povo atua dessa maneira", "a minha organização faz tal ritual", há uma possessividade que pode ser traduzida como "a minha experiência".

No que concerne à interpretação, o etnógrafo sai do campo levando consigo textos, registros escritos, que deverão ser analisados em um outro momento, longe da experiência vivida. A emoção estará registrada em palavras e pode ser lembrada, mas não mais será sentida pelo pesquisador tal como o foi no momento da experiência.

Assim, há que se ter em mente que a subjetividade do etnógrafo perpassa tanto o campo como o relato acerca desse campo. Nas palavras de Clifford (1998, p. 43):

Conseqüentemente, nem a experiência nem a atividade interpretativa do pesquisador científico podem ser consideradas inocentes. Torna-se necessário conceber a etnografia não como a experiência e a interpretação de uma "outra" realidade circunscrita, mas sim como uma negociação construtiva envolvendo pelo menos dois, e muitas vezes mais, sujeitos conscientes e politicamente significativos. 
Kottak (1997) considera Clifford um antropólogo experimental e afirma serem esses antropólogos aqueles que reconhecem as etnografias como trabalhos que conjugam a literatura com a ciência. $\mathrm{O}$ aspecto literário se deve ao fato de o etnógrafo, por meio de seu texto, agir como mediador entre aquilo que acontece no campo - isto é, a cultura nativa - e o leitor. A polifonia tornou-se uma forma de dar voz aos informantes e evidencia o modo pelo qual o etnógrafo estabelece a sua relação com os nativos. Para Kottak (1997, p. 27):

A etnografia dialógica é um gênero dentro de uma categoria experimental mais ampla - a etnografia reflexiva. Aqui o etnógrafo-escritor põe os sentimentos e reações pessoais de sua vivência de campo diretamente no texto. [...] O etnógrafo deve adotar algumas das convenções do estilo novela, incluindo a narrativa na primeira pessoa do singular, as conversas, os diálogos e o humor.

Silva (2000) chama a atenção dos etnógrafos para uma faceta interessante: a linearidade proposta pelas etapas definidas como integrantes do fazer etnográfico. A ida a campo só deve ocorrer depois de definido o objeto e de lidos os primeiros documentos relativos ao objeto escolhido. Ocorre que, ao se estudar as sociedades complexas e, em especial, o contexto urbano, é bem provável que a ida a campo possa se dar bem antes da leitura dos documentos ou mesmo da definição do objeto. A saída do campo em certas circunstâncias pode não se concretizar, pois o antropólogo tem a possibilidade de estabelecer relações que se prolongam mesmo após o término da pesquisa, como afirma Silva $(2000$, p. 27): "Na prática essas etapas são processos que se comunicam e se constituem de forma circular ou espiral".

Os recursos técnicos (máquinas fotográficas, filmadoras, gravadores) utilizados pelos etnógrafos em campo auxiliam no registro fiel das falas, dos rituais, de situações, imagens, mas, de qualquer forma, são perpassados pela subjetividade do pesquisador, que, ao escolher essa ou aquela situação para filmar, por exemplo, já está fazendo um recorte, selecionando entre inúmeras possibilidades. Vale destacar a posição de Silva (2000), que refere ser esse recorte também determinado pelos informantes, que muitas vezes vão definir o que pode ou não ser fotografado ou gravado. Nas palavras do autor:

[...] a utilização das técnicas de pesquisa ou da decisão sobre o que ver e ouvir, como registrar, não depende somente do antropólogo, mas da representação que os grupos observados fazem sobre essas técnicas e que determinam as restrições impostas ou os consentimentos dados. (SILVA, 2000, p. 59)

A interação do etnógrafo com os seus informantes vai se dar também de modo cíclico, ora com momentos de maior desconfiança, ora com mais empatia, certa reserva ou total solidariedade, tudo isso em uma mesma pesquisa. Os pesquisadores também são submetidos a certos 'ritos de passagem', considerados relevantes pelo grupo estudado e que irão determinar o tipo de relação estabelecido entre a comunidade e o pesquisador. No dizer de Velho e Kuschnir (2003, p. 9): "Compreender os lugares e os valores atribuídos ao pesquisador é também um modo de entender as crenças e representações dos integrantes do universo investigado acerca do mundo social".

\section{Delimitação do campo}

Nesta seção será apresentado aquilo que Baztán (1995) tratou como a 'delimitação do campo', que se refere às escolhas pelas quais se passou anteriormente à entrada em campo, no caso, a escolha da temática, da organização e dos informantes. Devido ao caráter pessoal do trabalho etnográfico e, portanto, das escolhas da pesquisa que serão aqui descritas, o texto que se segue será prioritariamente escrito na primeira pessoa do singular.

\section{Escolhendo o tema: a Antropologia do Corpo}

Para desvendar a cultura desse grupo social denominado empresa, os teóricos organizacionais, de uma segunda fase dos estudos de cultura, unem-se aos antropólogos modernos quanto à diversificada possibilidade de escolha das categorias a serem utilizadas para a apreensão da cultura. Essa postura está baseada no fato de as 
monografias antropológicas modernas priorizarem apenas um tema, por meio do qual toda a sociedade ou cultura passa a ser descrita, analisada e interpretada (OLIVEIRA, 1998) ${ }^{1}$. Não pretende, assim, retratar a totalidade de uma cultura, mas "somente ter em conta que a cultura, sendo totalizadora, mesmo que parcialmente descrita, sempre deve ser tomada por referência" (OLIVEIRA, 1998, p. 29).

É nesse contexto que pode ser entendida a atual existência de uma série de disciplinas na Antropologia, em que, apesar de se buscar sempre o conhecimento do 'outro', diferencia-se na escolha do tema a ser utilizado. Algumas disciplinas oferecidas pelo Programa de Pós-Graduação em Antropologia Social (PPGAS) da universidade na qual fazia minha pesquisa - parentesco, religião, corpo e saúde, consumo e dinheiro, arte, performance, entre outras - permitem que se perceba a gama de possibilidades que esse campo do conhecimento oferece aos seus pesquisadores e, no caso específico, aos integrantes de outras áreas.

Diante da necessidade de escolha de uma dessas temáticas e, partindo de uma idéia inicial de realizar minha pesquisa em uma instituição do setor de saúde, inscrevi-me na disciplina Antropologia do Corpo e da Saúde, oferecida por esse programa de pós-graduação. Durante boa parte do semestre, assisti às aulas na esperança de construir minha questão de pesquisa com base em algo que se relacionasse às organizações da área da saúde e à temática da cultura organizacional.

Conforme o tempo foi passando, percebi que outra questão de pesquisa poderia ser construída, uma que trouxesse a temática básica da Antropologia do Corpo para os estudos de cultura organizacional. É intuito dessa disciplina antropológica pensar a relação que se estabelece entre corpo e cultura, por se acreditar que a cultura é inscrita (perspectiva simbólica) ou incorporada (perspectiva fenomenológica) pelos sujeitos culturais e que, portanto, poderá ser desvendada (e politizada) em um processo interpretativo ou fenomenológico do pesquisador. A idéia que me surgiu, portanto, era: se a Antropologia do Corpo trabalha com o pressuposto de que a cultura é algo que se inscreve no corpo de seus sujeitos sociais (ou é incorporada por esses corpossujeitos); seria possível eu seguir o mesmo caminho, tratando, porém, da relação corpos dos trabalhadores e cultura organizacional?

De posse dessa dúvida fui conversar com minha orientadora, assim como com a própria professora da disciplina da Antropologia, de modo que elas avaliassem a possibilidade de minha pesquisa ser construída com base nesse tema. Como já havia realizado uma leitura prévia de diversos textos acerca da temática da cultura organizacional, tinha uma noção inicial de que não havia um aprofundamento nos estudos dessa área em relação à temática corpo-cultura, ou seja, tratava-se de uma proposta inovadora. Uma vez aprovada essa idéia inicial por ambas as professoras, construí minha primeira questão de pesquisa: como as culturas organizacionais se exteriorizam através dos corpos de seus trabalhadores? Meu objetivo geral ficou inicialmente definido como: desvendar as culturas organizacionais com base na análise simbólica dos corpos de seus trabalhadores. De posse dessa definição, comecei a realizar uma pesquisa teórica sobre o tema, assim como a pensar em qual organização e com quais sujeitos eu realizaria a pesquisa.

\section{Escolhendo a organização: uma livraria de shopping center}

Meu contato com a SerLivro, uma grande livraria de um shopping center da cidade de Porto Alegre, é anterior a qualquer intenção de pesquisa, ou seja, eu já a conhecia como cliente. Em uma de minhas visitas, já com a idéia de que minha pesquisa circularia pela temática do corpo, chamou-me atenção um vendedor do setor de CDs. Ele ornamentava seu corpo com um visual alternativo em relação ao padrão shopping center/Porto Alegre/Brasil. Suas tatuagens eram muitas e aparentes, seus cabelos eram compridos, com dreadlock, cada lóbulo de sua orelha continha um alargador. Ao ser atendida por ele, percebi que seu comportamento de vendedor não condizia com o estereótipo normalmente atribuído a pessoas com tal conjunto de ornamentos, o de uma atitude de irreverência. Ao contrário disso, em seu atendimento, ele apresentou uma fala tranqüila e atitudes de um funcionário disciplinado. 
Logo após o atendimento, resolvi circular pela loja, imaginando encontrar uma repetição desses ornamentos em outros vendedores. Percebi que outros tipos físicos também estavam presentes entre os vendedores, como, por exemplo, as socialmente aceitas 'loiras de cabelos longos e apenas um par de brincos em cada orelha'. Esse contexto de diferentes ornamentações em pessoas da mesma equipe se diferencia da média das empresas que fazem uso de regras bastante restritas de ornamentação, incluindo nessas o uso de uniformes. Essa postura destaca a homogeneidade tal qual um valor da modernidade que, por sua vez, perpassa diversos campos teórico-práticos, entre os quais as organizações certamente estão incluídas.

A constatação da possível perversão desse importante valor moderno deixou-me curiosa sobre a SerLivro. Comecei a me questionar se haveria uma relação entre esses corpos e a cultura dessa organização; caso houvesse, que valores levariam essa empresa a escolher tais corpos, e vice-versa. É, portanto, com base nessa experiência inicial que comecei a considerar a SerLivro como locus privilegiado para responder à minha questão inicial de pesquisa. Aliou-se a isso o fato de o projeto de pesquisa da minha orientadora junto ao CNPq ter por enfoque o estudo das culturas organizacionais de sebos e livrarias de Porto Alegre, o que se configurou também como um ponto favorável à escolha.

Cumpre destacar que, além da loja de Porto Alegre, a SerLivro conta com mais quatro lojas distribuídas por capitais brasileiras. Sua matriz e sua diretoria encontram-se alocadas na cidade de São Paulo. Na época da pesquisa, a SerLivro possuía uma equipe de aproximadamente 650 funcionários e um acervo de livros, revistas, CDs e DVDs em torno de 700 mil itens.

\section{Escolhendo os informantes: os vendedores}

A escolha dos vendedores como foco principal de minha observação está imbricada na experiência recémnarrada de escolha da SerLivro como organização para se realizar a pesquisa. Foi por um olhar de estranhamento em relação aos corpos da equipe de atendimento que consegui juntar a temática, a questão e os sujeitos de pesquisa. Minha experiência anterior como gerente de uma empresa do setor de serviços foi, também, um auxílio nessa decisão. Eu havia organizado alguns programas de desenvolvimento junto à equipe de atendimento, e por muitas vezes ouvi as funcionárias utilizarem metáforas como 'cartão de visitas' ou 'vitrine da empresa' para se auto-conceituarem. Numa perspectiva antropológica, 'cartões de visita' e 'vitrines' são como artefatos organizacionais, ou seja, objetos nos quais uma parte importante da simbologia organizacional é apresentada e que, portanto, pode ser desvendada.

Do ponto de vista teórico, o estudo antropológico de Rodrigues (2000) também me incentivou a escolher os vendedores como equipe privilegiada na minha etnografia. Na análise da autora, o ato de compra e venda é um ritual que confere valor às mercadorias e em que o vendedor assume o principal papel de agente ritual, pois incorpora, com suas vestes, gestos e fala, os valores que a empresa almeja vender e que os clientes desejam comprar (RODRIGUES, 2000). Foi nesse contexto que elegi os vendedores da SerLivro como trabalhadoreschave para o estudo da relação cultura organizacional, corpo artefato e embodiment.

Além disso, minha escolha pela equipe de vendedores visava a corroborar os estudos de cultura organizacional que a compreendem valendo-se de sua heterogeneidade (GREGORY, 1983; CAVEDON, 1988; MELO, 1991; BRESLER, 1997; MARTIN e FROST, 2001; CAVEDON e FACHIN, 2002). Diferentemente dos estudos sobre cultura organizacional homogênea e corporativa (SCHEIN, 1984; TRICE e BEYER, 1984; FLEURY, 1991), os de cultura heterogênea acreditam na importância de se incluir os funcionários nos estudos culturais das organizações, uma vez que exercem influência sobre o processo organizacional mediante a forma como representam, experimentam e dinamizam os valores corporativos.

Tal é a idéia proposta por Gregory (1983): usar o ponto de vista do nativo pode levar a uma compreensão mais completa acerca dos fenômenos organizacionais, desvendando, assim, as inconsistências entre as posturas estabelecidas e os comportamentos usuais, entre as políticas formais e as práticas informais, entre a história oficial e a forma como esta é representada (assim como experimentada e dinamizada) pelos sujeitos 
organizacionais (MARTIN e FROST, 2001). Ao escolher os vendedores, portanto, busco compreender a cultura ao nível da ação organizacional, que é quando é aprendida, vivida e modificada.

Na época da pesquisa, a equipe da SerLivro compunha um total de 37 vendedores distribuídos nos onze setores de atendimento - técnicos, idiomas, humanas, literatura, esotéricos, literatura infanto-juvenil, artes, revistaria, clássicos, pop/rock e DVDs. Sobre a questão da idade, foi possível registrar que a média desses trabalhadores era de 26 anos; a vendedora mais nova tinha 18 anos e a mais velha, 36 anos. A idade mais recorrente foi de 27 anos, havendo um grupo de 7 vendedores com essa idade. Esses números demonstram o caráter jovem da equipe, que também é predominantemente do sexo masculino, com um total de 12 (32\%) mulheres e 25 (68\%) homens. Com relação à escolaridade, 15 (41\%) estavam cursando algum curso superior ou haviam trancado um curso superior anteriormente iniciado, 14 (38\%) já eram formados e apenas 8 (22\%) não estavam (pelo menos ainda) vinculados a uma instituição de ensino superior. Um título acadêmico, ou estar no ensino superior, representava um valor para esse grupo.

\section{Inserção em campo e registro sistemático}

Nesta seção será apresentado aquilo que Baztán (1995) tratou como momento de 'inserção em campo' e 'registro sistemático'. Para fins de descrever esse momento da pesquisa etnográfica, com base no campo SerLivro, foram construídos cinco itens que contemplam essa questão: "Entrada em campo", "Observação do campo", "Mudanças com o campo", "Entrevista dos informantes" e "Registro das informações". Devido ao caráter pessoal do trabalho etnográfico, o texto a seguir mais uma vez será escrito na primeira pessoa do singular.

\section{Entrada em campo}

Em novembro de 2004, fiz meu primeiro contato oficial com a SerLivro. Conversei com uma das coordenadoras de atendimento, Luciana, entreguei a carta de apresentação e, sem muitas perguntas e explicações, fui liberada para fazer a pesquisa. No dia 17 daquele mês, fiz minha primeira visita como etnógrafa: bloco de notas, caneta na mão e um "frio na barriga". Fui encaminhada por Luciana para o setor de CDs e DVDs, onde ela me apresentou apenas ao comprador. Depois vim a descobrir que ele exerce algumas funções de chefia no setor.

A equipe parecia ora curiosa, ora desconfiada com minha presença. Às vezes vinham me falar alguma coisa de bom sobre trabalhar na SerLivro, e, nessas horas, ocoria-me uma idéia do livro de Víctora, Knauth e Hassen (2000, p. 56-57): "Há uma tendência natural do pesquisado de oferecer respostas ao pesquisador que ele creia serem do interesse do último e assim apresentar uma falsa imagem de si, com o intuito de agradar ou valorizarse". Nesse primeiro dia, fiz observações num pequeno bloco, anotei algumas falas marcantes e conversei com alguns funcionários. Essas notas resultaram em nove páginas no meu diário de campo. Senti-me mais confiante.

No dia 19 de novembro, retornei já vestindo roupas apropriadas para o campo, ou seja, confortáveis e que imitavam os informantes com os quais tentava me relacionar, no caso: tênis, calça jeans e camiseta. Fui para o setor de CDs e DVDs e, pouco tempo depois de minha chegada, Luciana apareceu para dizer que meu acesso à empresa estava restrito à observação e que eu não poderia conversar com a equipe. Solicitou que eu trouxesse a relação de perguntas que faria aos funcionários, pois ela enviaria esse material para que a direção analisasse. Conversamos e decidimos que eu enviaria um resumo de meu projeto e que só retornaria à livraria quando tudo tivesse sido aprovado.

Dia $1^{\circ}$ de dezembro, retornei à loja com o projeto resumido, uma lista de atividades de pesquisa e, novamente, com a carta de apresentação. No dia 20 , fiz uma nova visita para verificar se já havia alguma resposta, mas não havia. Foi apenas no final de janeiro de 2005 que fiquei sabendo, em uma visita à loja e uma conversa com Luciana, que o diretor, Sebastião, estivera em Porto Alegre na semana anterior e que gostaria de conversar comigo. Sugeri a ela que marcássemos uma conversa telefônica, ela ficou de organizar. 
No início de fevereiro de 2005, consegui falar pela primeira vez com Sebastião. Ele parecia receoso em relação à pesquisa e foi bastante direto nas perguntas: "Mas o que você quer?" (notas de campo, fevereiro de 2005). Tentei responder de forma teórica e expliquei o método de pesquisa. Não foi suficiente. Ele pediu que enviasse um modelo do questionário que eu utilizaria com os vendedores e disse que não seria possível eu fazer observação participante, pois o trabalho já estava totalmente distribuído entre a equipe.

Em março, tive minha segunda conversa telefônica com Sebastião. Ao contrário de minhas expectativas negativas, ele havia aceitado que eu fizesse a pesquisa na livraria com a ressalva de que eu só poderia observar, não participando da rotina das tarefas. Finalmente, a negociação estava fechada. O longo período de duração das negociações remeteu-me ao depoimento da antropóloga Rita Amaral para o livro de Silva (2000, p. 43):

Coisas maravilhosas que qualquer iniciante deve saber quando vai ao campo: Ele deve saber que quando ele ligar para um pai-de-santo para marcar uma entrevista, vão fazer você ligar cinqüenta vezes para marcar. Porque o pai-de-santo vai estar ocupado, matando, sacrificando, atendendo, ele não pode falar com você porque ele está descansando, ele quer saber quem você é, de onde você é. Você fica falando com um assistente durante quinze dias. Depois de quinze dias ele defere uma entrevista para você... Aí você vai lá e espera quatro horas sentado na parte de fora da casa. (O que eles não sabem é que a gente fica observando a clientela enquanto isso). Nada se perde numa tese, como diz Umberto Eco; até o tempo da sala de espera serve...

Combinamos, eu e Sebastião, um encontro na loja de Porto Alegre para nos conhecermos e combinarmos alguns detalhes. Uma das coisas que negociei com ele nesse encontro foi iniciar o campo no semestre seguinte, pois ainda tinha algumas etapas teóricas de minha pesquisa a cumprir. Apesar disso, ainda no mês de março de 2005, participei de um treinamento para novos funcionários Ali, realizei entrevistas com cinco vendedores e com um comprador e fui convidada por um dos entrevistados para ir até o 'fumódromo', ${ }^{2}$ onde conversei com alguns membros da equipe. O propósito de fazer essas entrevistas antes de iniciar a observação era o de criar vínculo com alguns informantes e, ainda, o de me inspirar para o detalhamento do projeto de tese que escreveria nos próximos meses.

Com o intuito de marcar essas entrevistas, pedi a outro coordenador de atendimento, Celso, que colocasse um recado no correio eletrônico me apresentando e convidando vendedores para a realização de uma entrevista de cunho acadêmico. Duas pessoas responderam: Nadir e Cristian. Terminada a entrevista, pedi para ambos que me recomendassem a um ou dois colegas de trabalho. Nadir me recomendou para Thomas e Andréia, e Cristian para Ismael. Além desses, a participação no treinamento de novos funcionários colocou-me em contato com Flávio. Após longa conversa, perguntei se ele gostaria de ser entrevistado, ele aceitou.

Realmente, essas cinco entrevistas foram muito importantes no posterior processo de aculturação com o grupo. Algumas dessas entrevistas foram bastante intensas em termos de declarações sobre a vida do entrevistado ou sobre a relação deste com a empresa; outras nem tanto. De um modo ou de outro, eram seis pessoas que eu conhecia e que me conheciam de uma maneira mais intensa e menos formal. A todos, expliquei minha pesquisa e o fato de que voltaria, no segundo semestre, para fazer a observação participante. Durante o tempo que fiquei afastada, visitava a loja e fazia questão de procurar todos os entrevistados para dizer que, em algum momento, eu retornaria. Numa dessas visitas, Nadir disse: "Não vai nos abandonar!"

\section{Observação do campo}

No início de agosto de 2005, retorno ao campo, ficando lá até dezembro. Em janeiro e fevereiro de 2006, também vou à livraria, porém, dedico-me mais à realização de entrevistas. Enviei uma carta semelhante àquela que havia escrito em fevereiro de 2005, para novamente me apresentar à equipe da SerLivro de Porto Alegre e falar um pouco mais da minha pesquisa. Desta vez, senti-me mais aceita pelo corporativo, pois recebi um crachá, com a inscrição de 'visitante', um armário para guardar meus pertences, acesso à copa, aos banheiros e a outros espaços exclusivos aos funcionários. 
Com o passar do tempo, talvez por estar portando um crachá semelhante aos dos vendedores, comecei a ser solicitada por clientes para indicar livros ou, simplesmente, mostrar a localização de outras seções da livraria. Além disso, passei a oferecer ajuda aos meus 'colegas' vendedores em tarefas como organização de prateleiras e busca de livros que haviam sumido. Esse ponto refere-se à reciprocidade que o etnógrafo deve construir com os sujeitos de pesquisa, pois no campo estamos sempre negociando o dar e o receber (MAUSS, 2003). Demonstrar, de fato, interesse em ajudar e efetivamente 'botar a mão nos livros' colaborou para a aceitação de minha presença por parte dos funcionários, além de facilitar a observação e a vivência dos imponderáveis da vida desses vendedores de shopping center.

A impossibilidade de cumprir uma jornada de trabalho tão longa quanto a deles, por outro lado, trouxe certo afastamento em relação à realidade de vida desses trabalhadores. A jornada de trabalho dos vendedores da SerLivro é de 44 horas em seis dias por semana, ou seja, há apenas uma folga semanal - nunca aos sábados e apenas uma vez ao mês aos domingos. Como não foi possível acompanhar essa demanda organizacional, muitas vezes escutei falas como "Tava sumida!" e "Quanto tempo!?!" (notas de campo, diversas datas), quando eu havia ficado apenas um ou dois dias sem ir a campo. Entretanto, se, por um lado, essa fala demonstrava meu afastamento em relação às reais condições de trabalho de meus informantes; por outro, ela também sinalizava uma aceitação de minha presença em campo. Para compensar essa não presença, diversifiquei meus horários, participando tanto da rotina da manhã quanto da noite, tanto dos dias de semana quanto dos sábados, domingos e feriados.

Com o intuito de melhor conhecer algumas dinâmicas corporais dos funcionários da livraria, almocei e lanchei por diversas vezes com alguns membros da equipe, nos diferentes lugares por eles eleitos como adequados: copa da empresa, praça de alimentação e restaurante vizinho ao shopping. Além disso, participei de atividades de lazer, principalmente aquelas referentes a um grupo específico de funcionários, o Lado-B. ${ }^{3}$

A programação de lazer desse grupo era vinculada a eventos noturnos, como longos e intensos happy hours, uma festa na casa de um 'colega', uma festa de bar na qual esse mesmo 'colega' era DJ, uma festa de aniversário de um dos membros do grupo, ocorrida em uma tradicional casa noturna da cidade, e um show de rock. Neste último, acompanhei, principalmente, alguns membros da equipe dos CDs. O grupo de funcionários pertencentes ao Lado-B é o que mais me acolhe e com o qual mais me identifico durante minha permanência em campo.

Minha primeira participação em um evento corporativo ocorreu em um treinamento para novos funcionários. Além deste, foi-me permitido observar um processo de seleção de vendedores, três reuniões com a direção da empresa e, ainda, participar da festa oficial de Natal. Resumidamente, posso dizer que observar essas duas dimensões da vida desses vendedores - em ambientes formais e informais - ajudou-me na compreensão da problemática desta pesquisa, que se refere à análise da relação existente entre cultura organizacional, corpo e embodiment.

\section{Mudanças com o campo}

Não apenas os corpos dos vendedores e de outros funcionários da SerLivro ocuparam espaço nas minhas análises de campo; eu, um corpo-sujeito, também fui considerada. Ainda na fase de campo, comecei a observar o quanto eu estava incorporando o ethos oficial e não oficial da SerLivro. Por oficial, considero o modo de (corporalmente) se comportar, principalmente dentro do ambiente de loja, e por não oficial, o querer trazer minha participação nos momentos de lazer dos 'colegas' do Lado-B. Nesta seção vou narrar um pouco sobre essa situação de campo.

Minha ida a campo, cabe lembrar, tinha como propósito inicial desvendar os aspectos representacionais da cultura da instituição que eu pesquisava. No caso, buscava desvelar a cultura da SerLivro pela análise simbólica do corpo de seus vendedores. Lembro que, ainda na fase de negociação com a diretoria, encontrei com um vendedor da SerLivro, no 'fumódromo', para o qual expliquei minha pesquisa. Conversamos sobre como seria 
interessante eu tirar algumas fotografias do grupo; ele comentou que eu deveria tirar fotografias de mim mesma: uma do antes de entrar na SerLivro e outra do depois. Talvez por causa desse comentário do 'colega', talvez inspirada pelo trabalho de Bresler (1997), que incluí a análise simbólica de sua própria vestimenta em seu campo etnográfico; adotei a conduta de anotar, em meu diário, a roupa que havia escolhido para ir ao campo, as roupas que comprara no decorrer do trabalho de pesquisa, minhas escolhas alimentares, meus movimentos, minhas posturas, entre outras tantas questões.

Como conseqüência desse procedimento, a análise simbólica que realizo baseando-me nos corpos dos vendedores está totalmente imbricada com a apreciação daquilo que acontecia comigo mesma no campo. As mudanças pelas quais passava à medida que me tornava mais próxima do grupo eram parte importante da interpretação das informações etnográficas. Cabe ressaltar, entretanto, que a minha participação nas análises não tinha intuito etnocêntrico. De modo contrário, elas serviam como fonte de estranhamento e, portanto, de melhor separação entre o que era êmico (dos pesquisados) e o que era ético (do etnógrafo).

Uma das coisas que percebo nessas anotações é que eu não usava mais sapato com salto para ir à livraria. Essa informação está diretamente relacionada a uma das mais constantes práticas corporais dos vendedores da SerLivro: o 'ficar em pé'. Informações sobre essa dinâmica apareceram já no primeiro dia de campo, talvez pelo fato de eu usar um sapato com um pequeno salto - o que tornou minha observação bastante desconfortável. Sobre isso escrevi no meu diário: "Ficam em pé o tempo todo! Não dá para vir de salto!", e ainda: "Será que é tão desconfortável para eles quanto é para mim?" (notas de campo, novembro de 2004). Ficar em pé, a partir das minhas análises, demonstra ser mais do que uma postura 'natural' do corpo; é, na realidade, um valor corporativo a ser absorvido pelos funcionários. No caso do vendedor, o ficar em pé oferece prontidão de atendimento aos clientes, que usufruem de um vendedor desvencilhado de qualquer aparato imóvel e, mais do que isso, envia uma mensagem simbólica aos clientes de que aquele funcionário está pronto para atendê-lo.

Outra prática corporal de campo interpretada foi o 'ornamentar o corpo'. Além das diversas análises realizadas sobre o tipo de ornamentação privilegiado pelo grupo dos vendedores, percebi que algumas mudanças ocorreram comigo. Entre elas está a compra que fiz de um tênis All Star vermelho. Além de ser um tipo de sapato que proporciona conforto para o 'ficar em pé', analiso a escolha dessa marca e dessa cor como uma demonstração de que eu estava adquirindo um símbolo de pertença ao grupo que observava. Sobre o tênis All Star, busco o depoimento de Maurício, que fala um pouco sobre os significados dessa indumentária (entrevista, fevereiro de 2006):

E o All Star, eu engancho isso aí também, porque o All Star é uma coisa que tu usa com qualquer roupa, com jeans assim é... acho que é por isso que o pessoal gosta, porque é um tênis barato e tu usa com qualquer roupa e ele é confortável assim, né, normal. E meio que tá na moda também, voltou a moda do All Star, tá todo mundo usando.

Outro ponto que me chamou a atenção em relação a essa perspectiva da ornamentação foi o fato de ter parado de fazer luzes ${ }^{4}$ nos cabelos e de ter reduzido minha frequiência semanal à manicure. Essas decisões também faziam parte de um contexto de campo no qual esses modos de embelezamento eram menos valorizados, seja pelo seu elevado custo, seja pela significação simbólica que produzem. No caso, a incorporação do All Star ao meu vestuário, a exclusão das luzes e a redução da ida à manicure são analisadas como mudanças de ornamentação que me aproximariam de um ethos jovem, cult e intelectualizado.

Com o passar do tempo, entretanto, comecei a realizar algumas anotações sobre questões corporais próprias que pareciam extrapolar essa dimensão simbólica. A aquisição do hábito de correr pela loja para atender clientes, a participação ativa nas festas e rituais informais de meus 'colegas', ter voltado a fumar quando estava em campo, a mudança de meus hábitos alimentares: mudanças mais profundas que percebi estarem ocorrendo em virtude de minha convivência com este campo de pesquisa. Em um processo de amadurecimento teórico, 
comecei a intuir que essas informações poderiam ser analisadas de outra perspectiva de estudo da relação corpo, cultura, no caso, a de embodiment e cultura.

O 'correr pela loja', por exemplo, foi uma prática corporal bastante observada e, inclusive, vivenciada. Apareceu no material de campo de quatro dos seis meses de observação e na fala de cinco dos doze vendedores entrevistados. Comecei a perceber que eu mesma o estava praticando: "Apareceu um cliente para me pedir alguma coisa e eu corri para atender. Tenho percebido que isso se tornou um hábito meu, correr ou andar rápido para encaminhar alguma questão relacionada aos clientes. Vi a Silvana também correndo pela loja nesse dia" (notas de campo, setembro de 2005).

O meu envolvimento (corporal) com a equipe de vendedores da SerLivro também ocorreu em um espaço informal, nas saídas após o trabalho, também conhecidas como happy hour, fato exemplificado a seguir. Durante um dos encontros, o mais festivo de todos, os participantes estavam bastante integrados. Essa integração pôde ser observada pelo aumento no tom de voz das conversas e risadas, pelos abraços e beijos trocados entre muitos, pelos passos de dança que começaram a ser conduzidos, além do perceptível aumento de consumo de cigarros por parte dos fumantes e, inclusive, de mim, que até aquele momento era uma ex-fumante. Uma cena do diário de campo relata esse contexto:

A essas alturas, a mistura de cerveja, afeto e alegria me faz pedir gritando "Me dá um cigarro!", solicitação que foi prontamente atendida. Chamou minha atenção que era o último cigarro da carteira de Vanderlei, mas ele falou para eu não me preocupar que iria comprar outro. Fumei muitos cigarros, o primeiro foi mais difícil (eu havia parado de fumar alguns meses antes), mas os demais foram tranqüilos, fumei com gosto. Nem senti a diferença entre Free e Carlton, só cuidei para não fumar Malboro que é mais forte. (notas de campo, novembro de 2005).

Após um consumo de aproximadamente cinco cervejas por participante, pagamos a conta e nos encaminhamos à saída. Quando o grupo descia as escadas do estabelecimento, percebi que quase todos haviam colocado óculos de sol, embora fosse noite e estivessem dentro de um shopping center. Começaram a soltar falsas gargalhadas em sinal de protesto às queixas do segurança do estabelecimento por causa da 'festa' que estávamos fazendo. Uma cena do meu diário de campo relata a minha integração (corporal) na finalização do encontro:

Fomos para o carro, sete pessoas apertadas e Depeche Mode tocando em volume alto. Flávia cantava e dizia em voz alta "Depeche é tudo!". A essas alturas eu também tinha colocado os óculos escuros para acompanhar meus colegas de ritual. Falávamos alto, fumávamos e sacudíamos os corpos como se tentássemos dançar no pequeno espaço disponivel. Ninguém se orientava muito sobre o caminho que devíamos tomar, a euforia era maior do que a preocupação com o retorno para casa. (notas de campo, novembro de 2005)

Cabe destacar que sou tida por meus amigos como pouco festeira, e como alguém que combina para sair e, quase sempre, cancela na última hora. $\mathrm{O}$ ambiente festivo do grupo, entretanto, me cativou. Assim como meus colegas de ritual, eu estava eufórica, feliz com toda aquela agitação e sem vontade de voltar para casa.

Desse modo, a relação estabelecida entre 'meu' corpo como pesquisadora e a cultura da SerLivro - seja pela dimensão simbólica ou pela perspectiva do embodiment - foi incluída na minha agenda de pesquisa. Na realidade, destacar a importância de se trazer o corpo do pesquisador para o processo de formação de conhecimento em Administração já havia sido levantado por Martin (2002) em seu trabalho sobre a questão estética das organizações. A área da cultura organizacional, entretanto, não tem oferecido o devido destaque a essa questão.

Ao adotar a postura de analisar meu próprio processo corpóreo de inserção em campo, acabo por me aproximar de uma premissa importante do método fenomenológico: a inclusão da historicidade do próprio investigador no processo de pesquisa. Esse é um método pelo qual é possível focar-se em uma análise qualitativa do objeto, ou 
seja, em que a preocupação não está em medir, dissecar e calcular o objeto mas, sim, em compreendê-lo. Mais do que isso, é um método no qual não se separa tão claramente o sujeito pesquisador do objeto pesquisado, visto que esse método está diretamente relacionado às próprias peculiaridades do sujeito (no caso um corposujeito) e do objeto a serem considerados.

\section{Entrevista dos informantes}

Tendo como pressuposto que o olhar por si só não é suficiente para perceber a natureza das relações sociais mantidas entre as pessoas (OLIVEIRA, 1998), vali-me do recurso da entrevista para a obtenção de outros tipos de informações sobre os vendedores da SerLivro. Realizei entrevistas com doze vendedores, um comprador, os três diretores e o encarregado dos recursos humanos (RH).

As entrevistas com os vendedores e o comprador eram semi-estruturadas e foram realizadas em dois encontros. No primeiro, o objetivo era aprofundar o conhecimento da rotina corporal que esses sujeitos estabeleciam tanto nos dias de trabalho quanto nos de folga. A questão que eu colocava para o entrevistado era: "Descreva com o máximo de detalhes um dia de trabalho e outro de folga, desde o momento em que tu acordas até quando tu vais dormir". O objetivo era conhecer, pela fala do entrevistado, partes da rotina que não era possível alcançar na observação participante, mas que poderiam ser importantes para compreender um pouco mais da relação corpo-organização. Para direcionar à temática do corpo, durante a fala do entrevistado, sugeria que ele aprofundasse alguns itens como alimentação, ornamentos, saúde, medicação, sono, entre outros.

No segundo encontro, a intenção era conhecer a história de vida do entrevistado, suas experiências anteriores e como ele havia chegado à SerLivro: "Fale um pouco sobre sua trajetória de vida até sua chegada na SerLivro". A partir daí, algumas perguntas se direcionavam para as mudanças que o entrevistado acreditava terem ocorrido na sua vida e no seu corpo com a entrada na livraria. "Tu acreditas ter mudado, inclusive em termos corporais, após a entrada na SerLivro?" e outras se direcionavam para a temática dos atributos de entrada e permanência tanto na SerLivro quanto no setor em que atuava: "Quais os atributos que tu tens, inclusive corporais, que facilitaram tua seleção e permanência na SerLivro e, mais especificamente, tua alocação no setor $x$ ?". Quando o tempo permitia, incrementava o questionário perguntando sobre o que é ser vendedor na SerLivro, sobre o que é o corpo do vendedor e sobre os planos futuros do entrevistado.

As entrevistas foram realizadas dentro e fora da empresa. Essa variação ocorria em virtude de uma preferência do entrevistado ou, em alguns casos, de um pedido específico por mim realizado devido à dificuldade de negociar horários de entrevista com a empresa. Com exceção das cinco entrevistas feitas antes do campo, em março de 2005, as demais foram obtidas no final de minha permanência na empresa entre novembro de 2005 e fevereiro de 2006.

Não foi possível realizar a segunda fase da entrevista com dois dos doze funcionários entrevistados, em razão de um ter pedido demissão e outro não ter mostrado interesse em continuar. O método de registro das entrevistas também mudou. Se nas primeiras optei apenas por anotar, pois os entrevistados pouco me conheciam e considerei que o gravador poderia inibi-los, nas demais optei por gravar, acreditando que a convivência com eles minimizaria seus medos e os vieses.

Buscando ter um contato com a diversidade da SerLivro Porto Alegre, escolhi os outros oito entrevistados com base em dois critérios de organização da equipe: um corporativo e outro informal. O critério corporativo foi a organização por setores, ou seja, busquei pessoas dos diversos setores nos quais produtos e pessoas estão distribuídos. O critério informal foi o de buscar pessoas de ambas as categorias êmicas: o Lado-A e o Lado-B.

Tive apenas um encontro, em separado, para a entrevista com cada um dos três diretores e com o encarregado do RH. Era uma entrevista semi-estruturada com o objetivo de conhecer algumas expectativas do grupo estratégico da livraria em relação à equipe de vendedores: "Qual é a expectativa, inclusive em termos corporais, que a direção tem em relação aos vendedores da SerLivro?" As entrevistas com o corporativo variaram em termos de método de registro das informações; tiveram duração de aproximadamente uma hora e, com exceção 
da entrevista do encarregado do RH, que foi realizada em São Paulo, as demais foram feitas na própria loja de Porto Alegre.

\section{Registro das informações}

Conforme brevemente comentado, durante a observação participante, utilizava um bloco para anotar palavraschave, falas ou breves observações que serviriam de base para o diário de campo. O bloco de notas era pequeno, de modo que coubesse no bolso de minha calça. Não carregar nada na mão era importante no meu campo, uma vez que este demandava muita flexibilidade e movimentação. Quando surgia uma cena interessante ou uma fala que representava uma categoria êmica, retirava o bloco de meu bolso, pegava a caneta que estava presa no cordão do crachá e fazia a anotação. Por muitas vezes, vi meus informantes demonstrarem desconforto ou curiosidade quanto ao que eu anotava: "me sinto uma cobaia" (notas de campo, outubro de 2005), disse Carina sobre eu estar anotando; e "o que tu tem nesse caderno?", me perguntou Marcelo (notas de campo, novembro de 2005). Nessas situações, eu tinha por hábito abrir meu bloco e mostrar a anotação atitude bem vista pela equipe.

Seguindo os ensinamentos de Malinowski (1997), as anotações de meu bloco tornaram-se um diário de campo que registrava com o máximo de detalhes a rotina, os imponderáveis, os sentimentos meus e de meus informantes. Como meu foco era a temática do corpo, muitas vezes utilizei desenhos para registrar posturas, roupas, ornamentos e, além disso, registrava o máximo possível de informações que me suscitavam algo sobre a relação corpo-organização. Buscava escrever o diário de campo em ambientes abertos ou perto de janelas, em uma atmosfera totalmente diferente daquela que comecei a considerar 'o claustrofóbico espaço de shopping center'. Posteriormente, este material de campo foi transcrito para o editor de texto Word.

As entrevistas foram, conforme já comentado, algumas vezes anotadas e, na maioria das vezes, gravadas. Tanto as anotadas quanto as gravadas foram posteriormente transcritas para um editor de texto. Eu mesma realizei este trabalho.

Por fim, cabe adicionar que, além das informações advindas do diário de campo e das entrevistas, vali-me de mais dois materiais de apoio: algumas fotografias que tirei da equipe no ambiente de loja e o manual de ingresso de novos funcionários. Foi necessário fazer um pedido à direção da empresa para tirar as fotografias, uma vez que é norma da empresa não permitir tal procedimento dentro da loja. Recebi autorização de Sebastião com a ressalva de que eu deveria pedir consentimento à equipe para uso da imagem. Algumas dessas fotografias foram utilizadas para ilustrar contextos de campo discutidos na pesquisa.

Contei, também, com o manual de ingresso de novos funcionários para obter algumas informações mais gerais sobre a empresa e como fonte para a breve descrição histórica da empresa. Além disso, utilizei o material explicativo acerca da filosofia e das diretrizes organizacionais (visão, missão e valor essencial). Essas últimas foram parte importante para a triangulação com as informações de campo (observação participante e entrevistas).

\section{Saída do campo e produção do relato}

Conforme afirma Baztán (1995), chega o momento em que o pesquisador, munido de uma gama considerável de informações sobre aquela cultura, deve deixar o campo para produzir o seu relato. Nesta seção será descrito o 'saindo do campo e produzindo o relato' (BAZTÁN, 1995) em forma de texto contínuo e, mais uma vez, utilizando a primeira pessoa do singular para a construção da narrativa.

De acordo com Malinowski (1978), o pesquisador deve dar conta de três áreas da realidade que constituem a totalidade da vida 'tribal': o arcabouço da constituição da sociedade (os registros escritos), os imponderáveis da vida real (as informações da observação) e o espírito do nativo (os depoimentos). Considerando que eu já havia explorado os manuais corporativos (os registros escritos), a vivência do campo numa perspectiva formal e 
informal (as informações da observação) e as entrevistas com vendedores e corporativo (os depoimentos); em fevereiro de 2006 considerei-me finalmente munida de uma gama de informações sobre a SerLivro e seus trabalhadores.

Nessa data deixei o campo, período no qual também me direcionei para uma temporada de estágio fora do Brasil. Houve, por um período de pelo menos nove meses, um afastamento quase total em relação ao meu campo de pesquisa. Mesmo tendo retornado para o Brasil, fiquei alguns meses sem vontade de voltar à loja $\mathrm{e}$ ver meus antigos 'colegas' de trabalho. Era como se naquele momento eu precisasse me afastar para que meu papel mudasse de 'colega' para pesquisadora. Nesse período, entretanto, mantive contato por e-mail com alguns; e com outros também utilizei esse modo de comunicação para enviar as fotografias que havia tirado no meu período de campo.

Num primeiro momento desse afastamento, fiz o esforço de repensar a problemática da pesquisa (questão e objetivos) para, então, iniciar o processo de organização das informações de campo. Assim, defini que separaria a pesquisa em dois grandes eixos teóricos - o corpo artefato e o embodiment -, os quais serviram de matriz principal para a organização do material empírico. Toda a informação acumulada - observações, entrevistas, manuais e diretrizes corporativas - foi transposta para o NVivo 2.0, um software de análise qualitativa. O material foi todo lido e simultaneamente organizado, principalmente nas categorias teóricas de 'corpo artefato' e 'embodiment', as quais, cada qual a seu modo, apresentavam suas respectivas subcategorizações. Essas subcategorias nada mais eram do que partes complementares e ilustrativas da idéia proposta pela categoria maior.

Uma vez organizadas as informações de campo, passei à produção do relato etnográfico propriamente dito. Nessa fase, já mais distante da experiência etnográfica, busquei organizar as situações de campo mediante contextos sócio-culturais mais amplos. A leitura do material empírico e a interpretação deste à luz de um conjunto teórico qualificado e abundante tornaram-se uma atividade extensa e prazerosa. Para cada interpretação acerca do campo, uma referência teórica vinha no sentido de corroborar ou problematizar a análise em questão. Durante o período dessa escrita, por vezes retornei a meu campo de pesquisa, e por vezes essa visita me levava a questionar algumas interpretações que fazia; já em outras foi como uma prazerosa confirmação daquilo que eu estava analisando.

Com relação à organização do relatório final da pesquisa, cabe mais uma explanação. A seqüência escolhida de apresentação dos assuntos se distinguiu da tradicional configuração dos trabalhos acadêmicos do campo da Administração, composta por referencial teórico, método, base empírica, discussão e conclusões. Optei por utilizar um modo de relato mais próximo do estilo dos estudos antropológicos. Primeiramente apresentei o método em um capítulo denominado "O campo de pesquisa: etnografia em uma livraria de shopping center". Depois, por trabalhar com perspectivas teóricas e modos de analisar as informações de campo de diferentes ontologias, construí dois grandes capítulos, divididos por temática, nas seções: "Teoria", "Campo" e "Discussão dos resultados". O capítulo dois, portanto, referia-se às análises teóricas e empíricas do corpo artefato, e o capítulo três trabalhava essas mesmas questões da perspectiva do embodiment. Em junho de 2007, finalizei o relatório de pesquisa.

\section{Contribuições da pesquisa para o conhecimento administrativo}

Ao relatar o caminho percorrido por uma das autoras deste artigo em sua pesquisa etnográfica, busca-se contribuir para a familiarização do pesquisador em Administração com a operacionalização desse método. Desse modo, procura-se mostrar de que maneira é alicerçado o conhecimento ao se fazer essa opção metodológica. Vale destacar que a forma como as informações são apresentadas, ou seja, numa perspectiva mais literária, bem como o repensar do pesquisador sobre a sua própria cultura, especialmente quando a pesquisa se desenrola em um ambiente urbano, faz parte do 'fazer etnográfico', sem esquecer é claro que as teorizações do campo antropológico é que acabam viabilizando o desvelar da cultura. 
Com o estudo etnográfico empreendido, foi possível trazer para a Administração todo o conhecimento adquirido pela Antropologia do Corpo, que busca, em um primeiro momento, desvendar (e politizar) a dimensão simbólica do corpo e, numa segunda fase, demonstrar que a relação pré-reflexiva (corporal) se constituí em uma relação entrelaçada mundo-sujeito-cultura. Sobre as análises decorrentes desse primeiro eixoteórico, a pesquisa contribuiu com a politização do corpo no ambiente organizacional, tanto da perspectiva do processo de preparação (disciplina) do corpo para o trabalho (o ficar em pé, o correr pela loja, o trabalhar doente, o comer e engordar, o ornamentar o corpo); quanto da perspectiva da hierarquização das diferenças corporais (a cor, a orientação sexual, a deficiência, a ornamentação, o volume do corpo). Ao politizar esse processo de 'gestão' desse corpo artefato, questionou-se um ordenamento maior do mainstream e da prática organizacional, principalmente os valores da instrumentalidade, da normalidade e da universalidade.

Sobre o segundo eixo-teórico da pesquisa, o embodiment, os resultados foram mais profundos. Ao demonstrar que existe uma relação pré-reflexiva, portanto corporal, entre trabalhadores da SerLivro e a cultura dessa organização, foi possível sugerir uma nova perspectiva de estudo da cultura organizacional. É a idéia de que antes de se tornar uma representação, ou seja, uma abstração mental, a cultura (inclusive a organizacional) é experimentada (incorporada) em uma vivência corporal não reflexiva. Resgatar o embodiment para os estudos de cultura organizacional, portanto, significa fornecer subsídios para a construção de uma nova teorização. Esta trataria o corpo como elemento central da cultura, pois é por meio dele (e não da razão) que se tem o primeiro contato com o mundo (inclusive o mundo das organizações), que é, desde sempre, histórico e cultural.

O intuito neste artigo, entretanto, não era apresentar com detalhes o resultado da pesquisa empreendida mediante a experiência etnográfica aqui descrita. Essa breve explanação visa a apenas apontar o quanto é possível conhecer e problematizar o espaço das organizações com um trabalho que se valha do método etnográfico.

Além da familiarização de outros pesquisadores em Administração com o método etnográfico, a produção deste artigo também teve como resultado destacar a importância de se considerar o corpo, do pesquisado e do pesquisador, como sujeito criador de conhecimento. Não é só a mente que constrói conhecimento, pois ela própria se constitui baseando-se em uma existência inicial pré-reflexiva (pré-objetiva), a qual torna possível a formação do pensamento racional e da cultura como sistema de representações. A construção do conhecimento em cultura organizacional não pode abster-se, desse modo de conhecer as organizações, um conhecimento que está enraizado no corpo. É necessário, pois, trazer a idéia metodológica de se considerar as percepções e reações do corpo como um aspecto central da aprendizagem sobre as organizações. Mais do que um artefato, o corpo tem a potencialidade de incrementar o conhecimento sobre experiência, aprendizado e mudança da cultura organizacional. 


\section{Referências}

BAZTÁN, A. A. Etnografia: metodología cualitativa en la investigación sociocultural. Barcelona: Marcombo, 1995.

BRESLER, R. A roupa surrada e o pai: etnografia de uma marcenaria. In: MOTTA, F. P.; CALDAS, M. (Org.). Cultura organizacional e cultura brasileira. São Paulo: Atlas, 1997.

CAVEDON, N. R. As manifestações rituais nas organizações e a legitimação dos procedimentos administrativos. 367f. Dissertação. (Mestrado em Administração) - Programa de Pós-Graduação em Administração, Escola de Administração, Universidade Federal do Rio Grande do Sul, Porto Alegre, 1988.

CAVEDON, N. R.; FACHIN, R. C. Homogeneidade versus heterogeneidade cultural: um estudo em universidade pública. Organizações e Sociedade, v. 9, n. 25, p. 61-76, set./dez., 2002.

CLIFFORD, J. A experiência etnográfica: antropologia e literatura no século XX. Rio de Janeiro: UFRJ, 1998.

FLEURY, M. T. L. Cultura organizacional e estratégias de mudanças: recolocando estas questões no cenário brasileiro atual. Revista de Administração, v. 26, n. 2 , abr./jun., p. 3-11, 1991.

GREGORY, K. L. Native-view paradigms: multiple cultures and culture conflicts in organizations. Administrative Science Quarterly, v. 28, n. 3, p.359-376, Sep., 1983.

KOTTAK, C. P. Antropologia: una exploración de la diversidad humana. Madrid: McGraw-Hill, 1997.

MALINOWSKI, B. Argonautas do pacífico ocidental. São Paulo: Abril Cultural, 1978.

Um diário no sentido estrito do termo. Rio de Janeiro: Record, 1997.

MARTIN, J.; FROST, P. Jogos de guerra da cultura organizacional: a luta pelo domínio intelectual. In: CLEGG, S. R.; HARDY, C.; NORD, W. R. (Org.). Handbook de estudos organizacionais. São Paulo: Atlas, 2001.

MARTIN, P. Sensations, bodies, and the 'spirit of a place': aesthetics in residential organizations for the eldery. Human Relations, v. 55, n. 7, p. 861-885, 2002.

MAUSS, M. Sociologia e Antropologia. São Paulo: Cosac \& Naify, 2003.

MELO, M. C. D. O. L. Produto e produtores da cultura organizacional: algumas questões sobre o comportamento dos empregados. Revista de Administração, v. 26, n. 2, p. 60-67, abr./jun., 1991.

OLIVEIRA, R. C. $O$ trabalho do antropólogo. São Paulo: Editora UNESP, 1998.

RODRIGUES, A. I. P. O ritual de venda e a performance dos vendedores do shopping center conjunto nacional de Brasília. In: TEIXEIRA, J. G. L. C. (Org.). Performance, cultura e espetacularidade. Brasília: Editora Universidade de Brasília, 2000.

SCHEIN, E. Coming to a new awareness of organizational culture. Sloan Management Rewiew, v. 25, n. 2, p. 3-16, 1984.

SILVA, V. G. D. 0 antropólogo e sua magia. São Paulo: Edusp, 2000.

TRICE, H. M.; BEYER, J. M. Studying organizational cultures through rites and ceremonials. Academy of Management Review, v. 9, n. 4, p. 653-669, 1984.

VELHO, G.; KUSCHNIR, K. Pesquisas urbanas: desafios do trabalho antropológico. Rio de Janeiro: Jorge Zahar, 2003. 
VÍCTORA, C.; KNAUTH, D.; HASSEN, M. Pesquisa qualitativa em saúde: uma introdução ao tema. Porto Alegre: Tomo, 2000.

${ }^{1}$ Oliveira (1998) lembra que as monografias clássicas da antropologia, diferentemente das atuais, tinham como pressuposto uma apreensão holística das sociedades na observação de seus contextos sócio-político-econômicos e culturais. Essa realidade, segundo o autor, pode ser percebida por uma disposição quase canônica dos capítulos - território, economia, organização social e parentesco, religião, mitologia, cultura e personalidade, entre outros.

${ }^{2}$ A expressão 'fumódromo' é um neologismo para designar lugares criados ou adaptados para se fumar cigarro. Tanto os ambientes quanto a expressão surgiram a partir de meados da década de 1990, quando se instaurou uma política (quase mundial) de combate ao fumo, tornando necessário separar, com maior ênfase, os fumantes dos não-fumantes.

${ }^{3} \mathrm{O}$ termo Lado-B se refere a um dos dois lados dos antigos LPs. Também alude aos tipos de músicas que eram normalmente gravadas nesse lado, músicas alternativas que não se tornariam sucesso de rádio. Neste campo, Lado-B se refere a como os componentes de um grupo de funcionários denominavam a si mesmos, ou seja, é uma categoria êmica (do informante). Para fazer parte desse grupo, eram importantes alguns elementos, como a detenção de um capital erudito, ter um papel de liderança frente aos demais colegas, ser (ou se achar ser) próximo à diretoria da SerLivro, apresentar um gosto classe média-alta, aceitar a diferença na orientação sexual, participar das festas dos demais membros do grupo e dos encontros de happy hour. Essa caracterização não foi dada por eles próprios, faz parte de um trabalho de interpretação do campo etnográfico. Em minha vivência com esse grupo, também foi possível perceber que sua composição não era estática, sofria variações com a admissão de novos funcionários com 'potencial' para se tornar Lado-B, com a demissão e o possível afastamento de colegas Lado-B ou, ainda, por processos cotidianos de negociação sobre quem é Lado-B ou Lado-A.

${ }^{4}$ Técnica pela qual se pintam pequenas mechas do cabelo; refere-se, geralmente, ao uso da tonalidade loira.

${ }^{5}$ Depeche Mode é uma banda de rock da década de 1980, que retorna ao mercado nesse início de século. 